\title{
Conforto ambiental sob membranas têxteis para coberturas tensionadas na região da Amazônia Legal
}

\author{
Environmental comfort under membranes textile fabrics for tensioned \\ Legal Amazon region \\ Confort ambiental bajo membranas textiles para cubiertas tensadas en la \\ región de la Amazonia Legal
}

\author{
Adriana Emiko Chiba Queiroz \\ Arquiteta e Urbanista, UFPA, Brasil. \\ adrianachiba@gmail.com \\ Alcebíades Negrão Macêdo \\ Professor Doutor, USC, Brasil. \\ anmacedo@ufpa.br
}




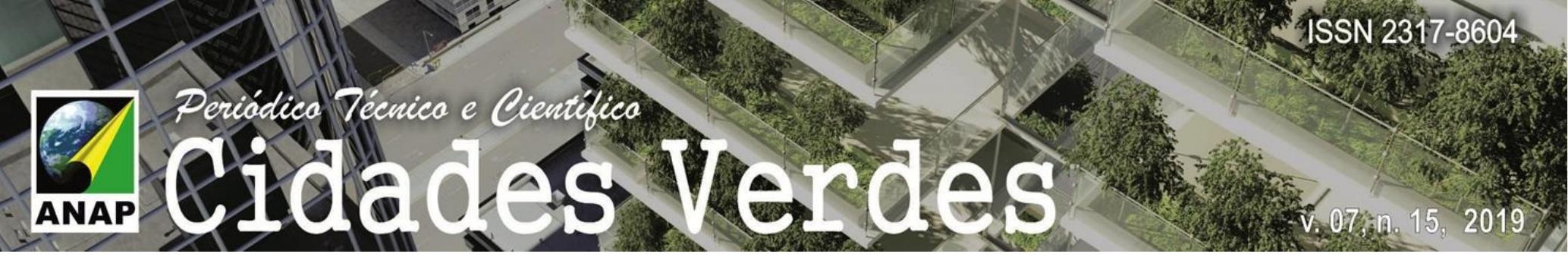

\section{RESUMO}

As coberturas tensionadas são confeccionadas com algum tipo de membrana têxtil e muitas vezes, estão apresentando desconforto ambiental para os usuários desta região em relação a outras regiões do Brasil e do mundo. Perante tantas opções de membrana têxtil é imprescindível investigar que parâmetro do material têxtil o define como adequado para se utilizar em projetos para região da Amazônia Legal. Este trabalho demostra a análise de vários materiais têxteis utilizados em coberturas tensionadas através de software, simulando em várias cidades que representam uma zona mesoclimática da Amazônia Legal e indicando os índices de membranas que se comportam adequadamente quando se trata de conforto ambiental para os usuários, dentre estes o índice de neutralidade apontou o parâmetro de reflexão como sendo o destaque para oferecer conforto ambiental, e o parâmetro de absorção como o de menor conforto ambiental para a região da Amazônia Legal . O estudo apresentou dois tipos de membrana têxtil com melhores condições de conforto térmico, a identificada como $n^{\circ} 18$ e 21 , foram as com maior índice de reflexão. Também apontou as duas menos adequada, as com maior índice de absorção, as de no 5 e 14 . Logo, existe a possibilidade de melhorias em termos de conforto ambiental, pela escolha correta do material a ser aplicado nas coberturas tensionadas, mesmo sabendo que há pluralidade de mesoclimas na região da Amazônia Legal.

PALAVRAS-CHAVE: Conforto ambiental. Membrana têxtil. Cobertura tensionada. Amazônia Legal.

\section{ABSTRACT}

The tensioned covers are made with some type of membrane and often presenting environmental discomfort to other regions. Faced with so many options of textile membrane, it is indispensable to investigate which textile material is the most suitable for using in projects for the legal Amazon Region. This research demonstrates the analysis of several textile materials used in roofing software, simulating in several cities that represent a meso-climatic analysis of the Legal Amazon and indicating the membrane parameters that act adequately when it comes to environmental comfort for users, among these the neutrality index pointed to the parameter of reflection as being the highlight to offer environmental comfort, and the parameter of absorption as the one of less environmental comfort for the region of the Legal Amazon. The study also presents types of textile membranes with better thermal comfort conditions, which were the ones with the highest levels of reflection, he one identified as ${ }^{\circ}{ }^{\circ} 18$ and 21 . We also pointed out the less appropriate two, which showed higher absorption rates, paragraphs 5 and 14 . Therefore, there is the possibility of improvements in terms of environmental comfort, by the correct choice of material to be applied in the tensile coverage, even though there are a number of meso-climates in the region of the Legal Amazon.

KEYWORDS: Environmental comfort. Textile membrane. Tensile coverage. Legal amazon.

\section{RESUMEN}

Las coberturas tensadas son confeccionadas con algún tipo de membrana textil y muchas veces, están presentando incomodidad ambiental para los usuarios de esta región en relación a otras regiones de Brasil y del mundo. Ante tantas opciones de membrana textil es imprescindible investigar qué parámetro del material textil lo define como adecuado para utilizarse en proyectos para región de la Amazonía Legal. Este trabajo demuestra el análisis de varios materiales textiles utilizados en coberturas tensadas a través de software, simulando en varias ciudades que representan una zona mesoclimática de la Amazonía Legal e indicando los índices de membranas que se comportan adecuadamente cuando se trata de confort ambiental para los usuarios, el índice de neutralidad apuntó el parámetro de reflexión como el destaque para ofrecer confort ambiental, y el parámetro de absorción como el de menor confort ambiental para la región de la Amazonia Legal. El estudio presentó dos tipos de membrana textil con mejores condiciones de confort térmico, la identificada como $\mathrm{n}^{\circ} 18$ y 21 , fueron las con mayor índice de reflexión. También apuntó las dos menos adecuada, las con mayor índice de absorción, las de no 5 y 14. Luego, existe la posibilidad de mejoras en términos de confort ambiental, por la elección correcta del material a ser aplicado en las coberturas tensadas, aun sabiendo que hay la pluralidad de mesoclimas en la región de la Amazonia Legal.

PALABRAS CLAVE: Confort ambiental. Membrana textil. Cobertura tensada. Amazonia Legal. 


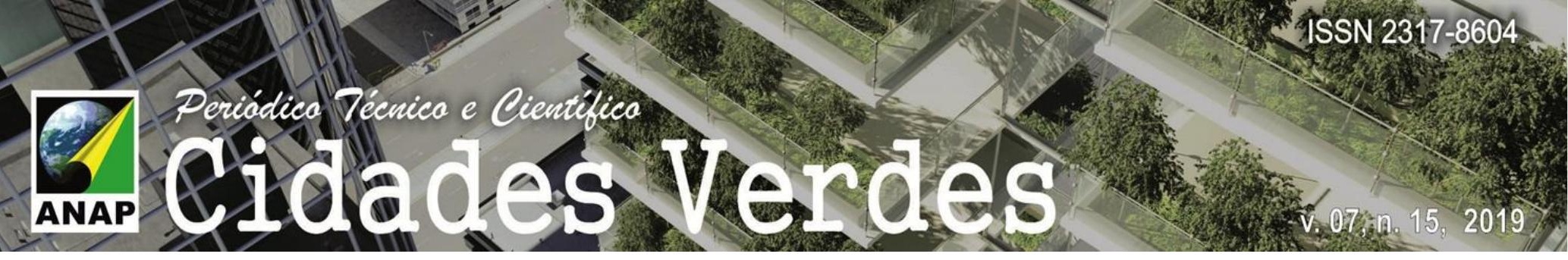

\section{INTRODUÇÃO}

Segundo o IBGE (2002), a região amazônica é caracterizada por zona tropical. E para os parâmetros da arquitetura sustentável, isso traz algumas imposições quando se pretende oferecer conforto térmico e luminoso naturais aos usuários em espaços semiabertos, como alpendres varandas e até mesmo tendas. Com tantos tipos de membranas têxteis, seria ideal especificar o mais adequado para atender essa pluralidade de mesoclimas que a região da Amazônia Legal expõe. Este trabalho fará a análise de vários materiais utilizados para coberturas tensionadas através de um software simulando em várias cidades amazônicas e filtrando os que mais se comportarem adequadamente quando se tratando de oferecer conforto térmico e luminoso para os usuários. A dissertação está organizada para oferecer parâmetros de conforto ambiental e características climáticas da região amazônica. Além de apontar a organização dos tipos de membrana e das coberturas tensionadas.

\subsection{JUSTIFICATIVA}

Com a informação tão mal difundida através dos diversos meios de comunicações do mundo moderno, houveram vários equívocos quanto a especificação de material a ser utilizado nas tenso-coberturas na região amazônica. Este trabalho aborda o problema da falta de dados comparativos quanto ao conforto térmico-acústico de uma tensoestrutura. O pressuposto do estudo é que com dados bioclimáticos do local onde será a instalação da tensoestrutura, a escolha do material seja mais assertiva, ao contrário de algumas obras encontradas em literatura ou exemplares existentes na atualidade para esta região. Apesar da proximidade da temática, com outros trabalhos este se diferencia pelo fato de procurar o lado aplicável da teoria. Indicar de forma cientifica qual ou quais características de materiais são adequadas para o uso como cobertura tensionada na região da Amazônia Legal. A principal justificativa deste trabalho é a realização da análise de comportamento ambiental dos materiais das membranas têxteis utilizadas em tensoestrutura. Para que haja uma normatização nas informações das composições dos materiais e suas reações comportamentais de conforto ambiental com relação ao ambiente instalado. Soma-se a isso o fato das tensoestruturas estarem voltando a ser opção entre os projetistas e o cuidado de não se tornar apenas um elemento estético e que pode influenciar de forma negativa naquele ambiente proposto ou construído. E também, a difusão de tensoestruturas em espaços permanentes é perceptível atualmente. Considerando o contexto atual onde membranas têxteis estão sendo comercializadas de todas as partes do mundo e do avanço da tecnologia nacional de confeç̧ão deste tipo de cobertura, este trabalho propõe de forma objetiva e direta o tipo adequado de material a ser utilizado no clima equatorial amazônico, por isso, aqui optamos por um modelo de tensoestrutura com formato simples, deixando de lado a análise do comportamento estrutural, para que a atenção seja voltada justamente para a análise do tipo de material de membrana de cobertura e seu comportamento quanto à temperatura e iluminação em um determinado local através de software específico para tal e apontando qual característica de material têxtil é mais adequado para coberturas tensionadas na região da Amazônia Legal. E neste mérito, a pesquisa traz a classificação destes materiais e filtra quais índices dos materiais devem ser levados em consideração para especificação adequada de membrana têxtil a níveis térmicos e luminosos na região da Amazônia Legal. 


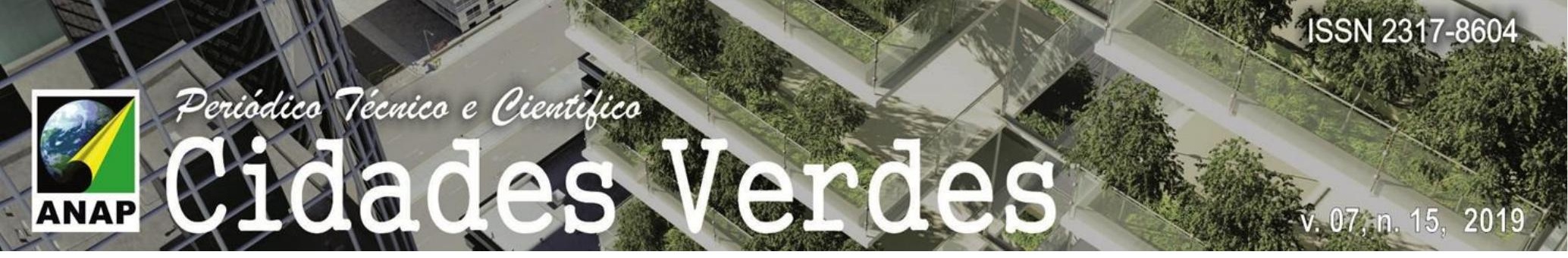

\subsection{OBJETIVO GERAL}

Definir quais os parâmetros e como seus índices devem ser levados em consideração para especificação de membrana têxtil de cobertura tensionada a ser utilizada na Amazônia Legal utilizando software para simular reações.

\subsubsection{OBJETIVOS ESPECÍFICOS}

- Definir os critérios a serem inseridos no software para coleta dos índices de 27 tipos de membrana têxtil em 7 cidades pertencentes a diferentes regiões mesoclimáticas da Amazônia Legal.

- Coletar e comparar os índices dos 27 tipos de membrana nas 07 cidades pertencentes a regiões mesoclimáticas diferentes da Amazônia Legal, e apontar quais os parâmetros destacados.

\section{MATERIAIS}

A Faculdade de Arquitetura e Urbanismo da USP e a Universidade Federal de Santa Catarina possuem laboratórios especializados em conforto térmico e eficiência energética. A FAUUSP inclusive publicou um estudo com título "Conforto térmico e luminoso em ambientes externos sob membranas têxteis tensionadas" e também mantém disponível para downloads os seguintes softwares: Climaticus, Chaminé, BD Acústica, Lux, Urbanus, Acústico, Humano, Fachada, Tensil e o Obstrução. Todos esses aplicativos são gratuitos e disponibilizados no link: <http://www.fau.usp.br/pesquisa/laboratorios/labaut/conforto/>. Já a UFSC disponibiliza os seguintes aplicativos: Analysis 1.5, Analysis BIO, Analysis SOL-AR, AvalCon-RIO, Declinação Magnética, Luz do Sol, Netuno, Psychros, ReZbBr, Sunpath, Transmitância, UMIDUS e o ZBBR Zoneamento Bioclimático do Brasil. Além do ensino e pesquisa dedicados ao conforto térmico pelo Laboratório de Eficiência Energética em Edificações. Diante desta variedade de aplicativos que poderiam substanciar o estudo de caso, vamos utilizar o seguinte software: Tensil 1.2. Segundo Alluci ([2006], p. 1), o software se dá da seguinte forma:

\footnotetext{
Este trabalho apresenta uma aplicação computacional que permite escolher membranas e dimensioná-las para estruturas tensionadas, a fim de proporcionar conforto térmico e luminoso. O banco de dados de características termo-luminosas de membrana foi desenvolvido através de pesquisas de campo e pesquisas em laboratório utilizando espectrofotômetro. A modelagem computacional consiste em: balanço termofisiológico, modelo de radiação, cálculo da temperatura do céu, cálculo das temperaturas superficiais do solo, vegetação e membrana. 0 índice de carga térmica foi adotado para avaliar o conforto térmico. No que diz respeito ao conforto luminoso, foram consideradas a transmissão por membranas e a contribuição do céu descoberto. O resultado final é uma aplicação computacional, com dados de 27 tipos diferentes de membranas e dados climáticos de 57 cidades brasileiras, que avalia o conforto térmico e luminoso de um dado ambiente, considerando: dimensões, atividades, membrana, características envolventes e cidade. A avaliação é feita a cada hora para um dia típico de cada mês do ano. A validação de software foi feita por meio de comparações positivas com resultados de dados empíricos coletados em pesquisas de campo.
} 


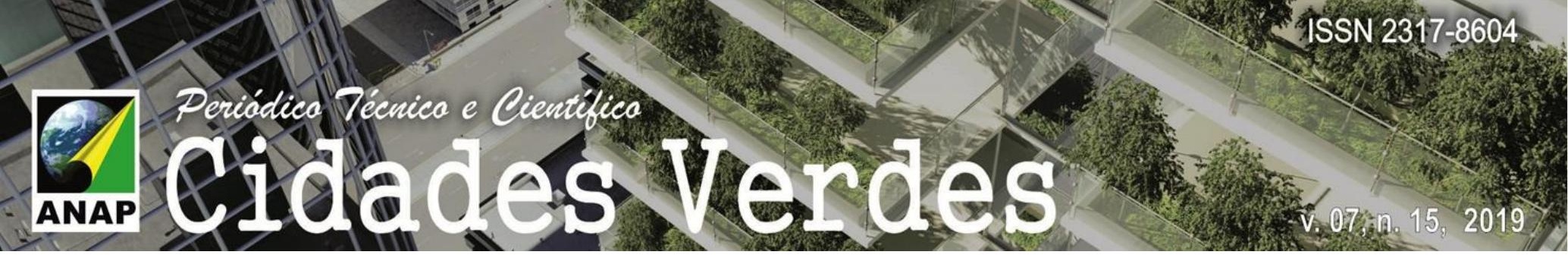

Atualmente, no site do Labee da USP está disponível a versão 1.2 do software, porém está corrompida. Em contato com o laboratório, explicaram que o erro se dava devido incompatibilidade de versões entre o Excel atual e o da época de elaboração do aplicativo. Mesmo seguindo as soluções sugestionadas, o erro permanecia. Foi então que entramos em contato direto com a criadora do software, Profa. Dra. Marcia Alucci, que mesmo aposentada, gentilmente nos enviou a versão 1.3 para darmos prosseguimento ao estudo, sendo que nas telas do software ainda aparece a marca Tensil 1.2.

\section{MÉTODOS}

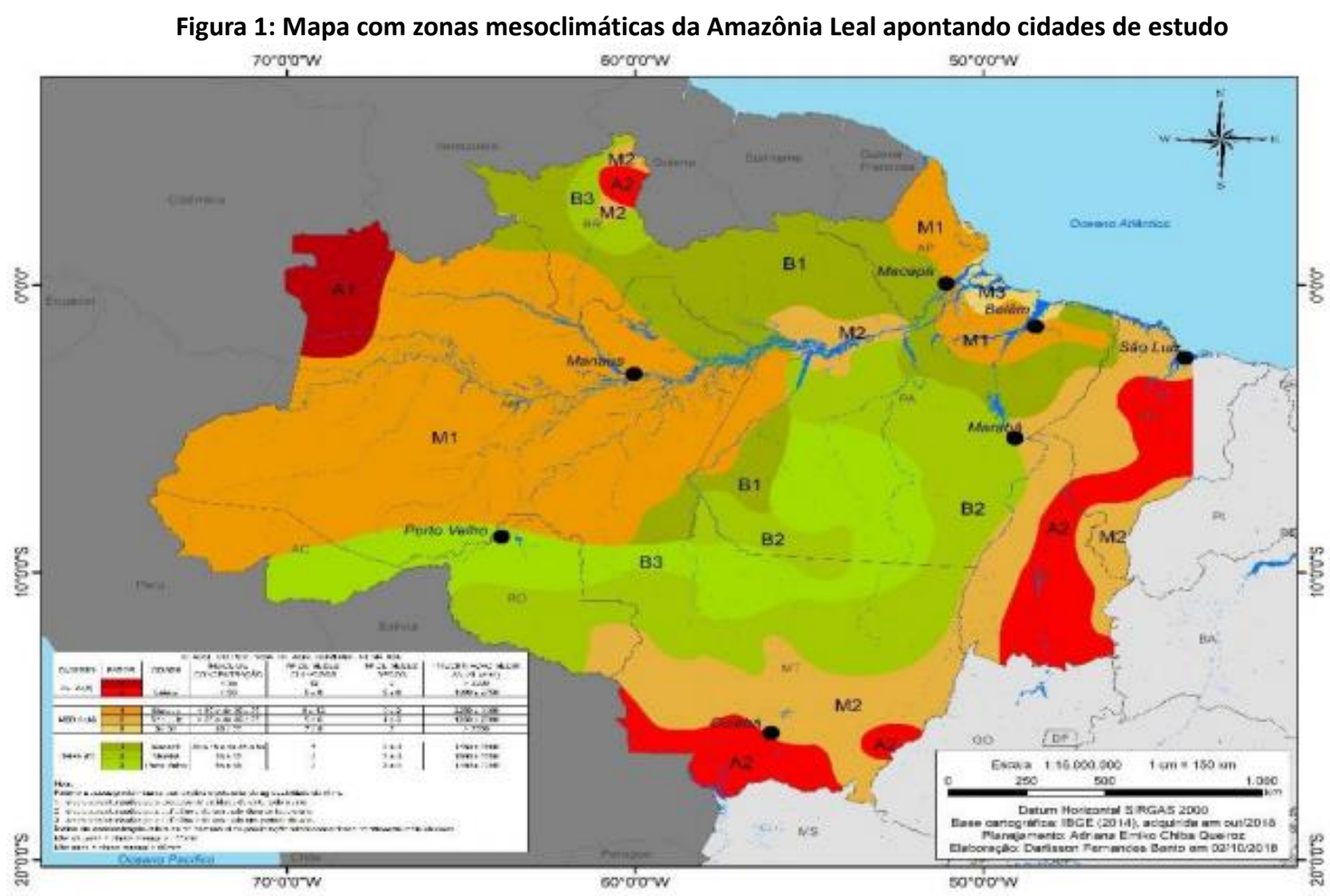




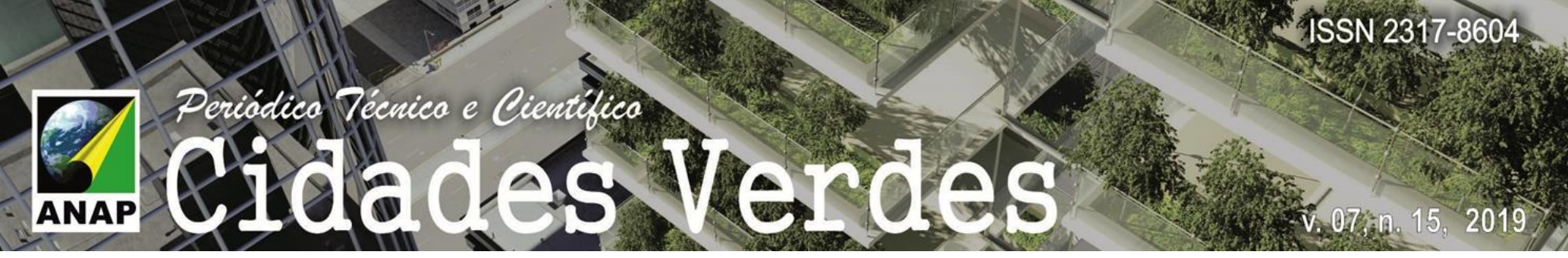

Fonte: Adaptado do IBGE, 2018.

Figura 2: Legenda do Mapa das zonas mesoclimaticas da região da Amazônia Legal da Figura 1.

\begin{tabular}{|c|c|c|c|c|c|c|}
\hline \multicolumn{7}{|c|}{ CLASSE DO POTENCIAL DE AGRESSIVIDADE CLIMÁTICA } \\
\hline CLASSES & FATOR & CIDADE & $\begin{array}{c}\text { ÍNDICE DE } \\
\text { CONCENTRAÇÃO }\end{array}$ & $\begin{array}{c}\mathrm{N}^{\circ} \text { DE MESES } \\
\text { CHUVOSOS }\end{array}$ & $\begin{array}{l}\mathrm{N}^{\circ} \mathrm{DE} \\
\mathrm{MESES} \\
\text { SECOS }\end{array}$ & $\begin{array}{l}\text { PRECIPITAÇÃO } \\
\text { MÉDIA ANUAL } \\
(\mathrm{mm})\end{array}$ \\
\hline \multirow{2}{*}{$\operatorname{ALTA}(\mathrm{A})$} & 1 & & $<35$ & 12 & 0 & $>3000$ \\
\hline & 2 & Cuiabá & $>55$ & 5 a 6 & 5 a 6 & 1000 a 2750 \\
\hline \multirow{3}{*}{$\begin{array}{l}\text { MÉDIA } \\
\text { (M) }\end{array}$} & 1 & Manaus & $<35$ e de 35 a 55 & 9 a 12 & 0 a 2 & 2250 a 3000 \\
\hline & 2 & São Luiz & $>55$ e de 45 a 55 & 5 a 6 & 4 a 5 & 1250 a 2000 \\
\hline & 3 & Belém & 45 a 55 & 7 a 8 & 3 & $>3000$ \\
\hline \multirow{3}{*}{$\begin{array}{l}\text { BAIXA } \\
\text { (B) }\end{array}$} & 1 & Macanó & 35 a 45 ede 45 & 8 & 203 & 1750 a 2500 \\
\hline & $\frac{1}{2}$ & Marabá & 45 a 55 & $\frac{0}{7}$ & 2 a 3 & 1500 a 2250 \\
\hline & 3 & $\begin{array}{l}\text { Porto } \\
\text { Velho }\end{array}$ & 45 a 55 & 7 & 3 a 4 & 1750 a 2250 \\
\hline \multicolumn{7}{|c|}{$\begin{array}{l}\text { Fator é a causa predominante que explica o potencial de agressividade do clima } \\
1 \text { - áreas caracterizadas pelo excesso de umidade durante todo o ano; } \\
2 \text { - áreas caracterizadas pela deficiência de umidade durante todo o ano } \\
3 \text { - áreas caracterizadas pela deficiência de umidade um período do ano. } \\
\text { Índice de concentração refere-se ao percentual da precipitação total concentrado no trimestre mais } \\
\text { chuvoso }\end{array}$} \\
\hline
\end{tabular}

Fonte: Adaptado do IBGE, 2018.

Para o estudo demarcamos uma gama de cidades pertencentes a região da Amazônia Legal, sendo que cada uma delas está em uma zona mesoclimática diferente conforme Figura 6 , com exceção da zona $A 1$, por não conter no software cidade localizada nesta região. $E$ capturamos dados no software para traçar as matrizes de sensação e comportamento ambiental para os usuários sob tensoestruturas com membrana têxtil das outras regiões de mesoclima conforme legenda no Quadro 1. Esta pesquisa tem objetivos comparativos e trata-se de Estudo de Caso de três formatos computacionais (Retangular $-R$, Quadrado - $Q$ e Circular $-C$ ) com a utilização de software específicos para comparação de 27 materiais de membrana para os mesmos três formatos e em cada uma das 7 regiões mesoclimática das regiões da Amazônia Legal. 0 estudo decidiu por parâmetros climatológicos, e índices de iluminancia e também por algumas características baseadas na cultura da região da Amazônia Legal. Pois o estudo se utilizou do software Tensil 1.3, para analisar que tipo de membrana têxtil seria adequado para a região supracitada em se tratando de conforto ambiental. A intenção de se predeterminar a região, neste caso, a Amazônia Legal, e apontar que tipo seria o ideal a ser utilizado evitaria inconsistências quanto a escolha do material nas instalações de tendas de clima diferenciado. Com estes dois parâmetros principais estabelecidos, selecionamos sete cidades que pertenciam a Amazônia Legal e com mesoclimas diferentes, são elas: Belém - PA, São Luiz - MA, Manaus - 


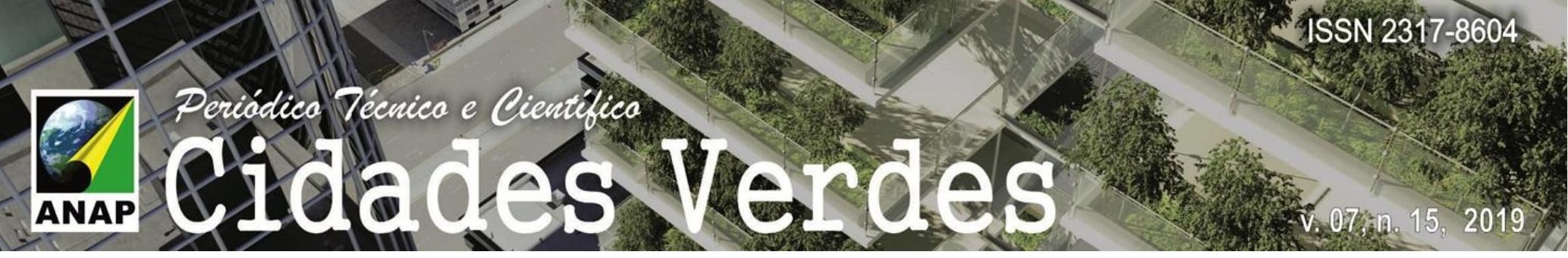

AM, Porto Velho - RO, Marabá - PA, Macapá - AP e Cuiabá - MT, cada uma delas em uma zona climática diferente de acordo com a classificação do IBGE, como mostra a Figura 6. Após determinar a cidade, foram inseridas várias características como descrito abaixo: - Área: área construída com edificações baixas, já que na Amazônia Legal ou até mesmo onde são instaladas este tipo de cobertura, geralmente o entorno construído tem baixa escala. - Revestimento de piso: o selecionado entre as opções disponíveis foi o cimentado, assim como no caso da cultura local e do uso deste tipo de empreendimento, geralmente podemos observar este tipo ou aproximado de material. - Atividade do Usuário: aqui consideramos o usuário em estado sentado, já que, geralmente neste tipo de instalação são exercidas algum tipo de atividade contemplativa que concernem o usuário a ficar sentado. - Tipo de Vestimenta: Especificamos a camisa de manga curta e calça comprida em tons médios, para os usuários, este também pela cultura adotada na região. Todas estas características determinadas indicava os índices de conforto urbano médio para o usuário que estivesse em região a céu aberto, demostrado em percentual que varia de uma escala que determina sensação de frio extremo, frio moderado, neutralidade, calor moderado e calor extremo. Antes da captação dos dados do estudo, foi necessário especificar em 300lux necessários para o ambiente sob a cobertura tensionada, logo determinando 180 lux para ambientes de iluminação natural, este dado considerou a NBR ISSO/CIE 8995-1 de 2013, que dita parâmetros de iluminância para ambientes internos. Esta normativa foi utilizada em função de não existir algo especifico para espaços semiabertos, neste caso, as tendas e em substituição a NBR 5413, que fora cancelada. Finalmente foram inseridas as características por tipo de geometria e dimensões da tenda. Quanto a estes dois últimos quesitos, optou-se por determinar a mesma metragem quadrada para os formatos retangular, quadrado e circular, por ser objeto do estudo apontar o tipo de material adequado e não avaliar se diferentes áreas cobertas por tenda estipulariam um mesmo tipo de membrana têxtil comum, então, não caberia estipular parâmetros de área coberta diferentes neste momento. A sequência de Figuras a seguir, de 7 a 11, demostra um exemplo de inserção de dados no aplicativo Tensil 1.3 nas diversas abas a serem especificadas antes da captura dos dados, apesar de na captura da tela ainda aparecer Tensil 1.2.

Para as sete cidades pesquisadas, cada uma inserida em uma zona climática diferente de acordo com o classificado no estudo Potencial de Agressividade Climática da Amazônia Legal do IBGE (2014), nos gráficos das figuras 3 aO 9 são identificados o tipo 18 e o tipo 21 como os mais adequados a nível de conforto ambiental ao usuário sob a estrutura de cobertura tensionada com membrana têxtil, onde visualizamos os maiores índices de Neutralidade como sensação. 


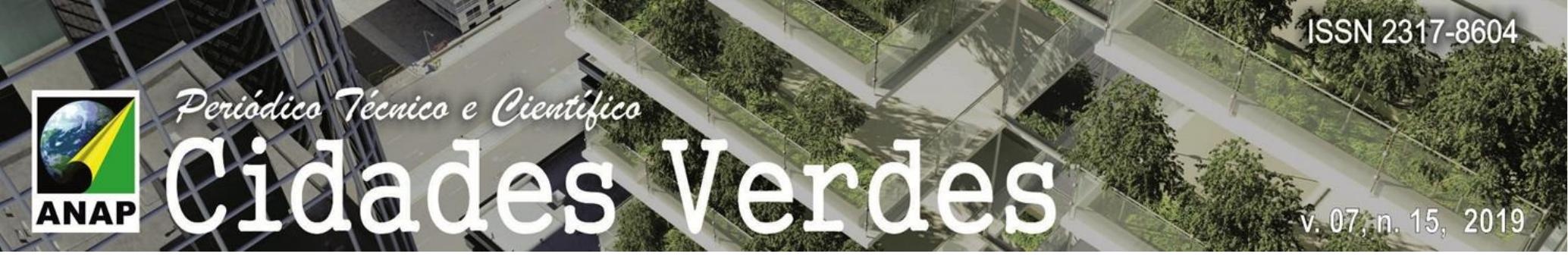

Figura 3: Gráfico apontando percentual de Neutralidade maior nas tipologias 18 e 21, e menor no tipo 5 - Cuiabá - MT.

Nivel de Conforto térmico sob Membrana Tensionada Cuiabá - MT (Zona A2)

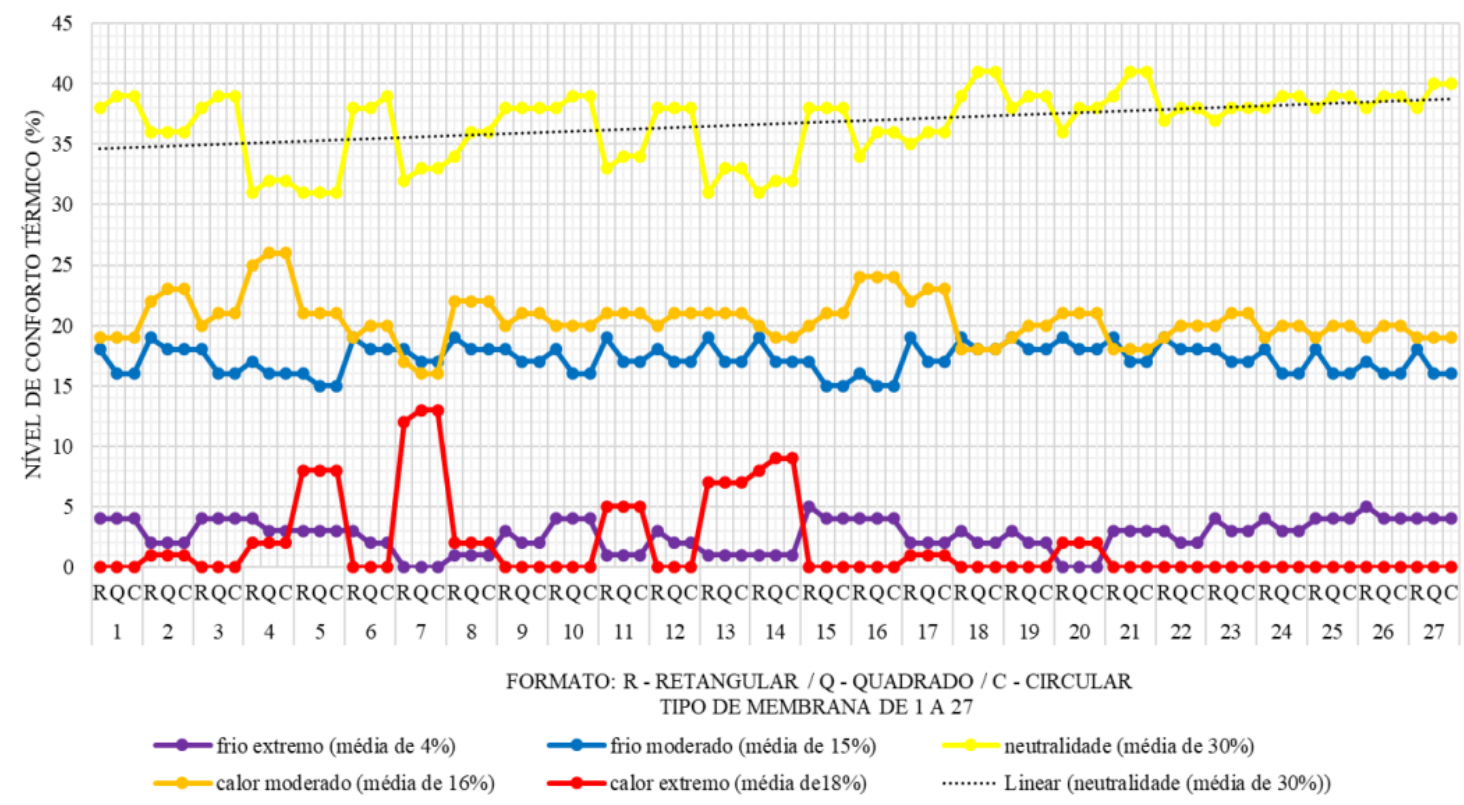

Fonte: AUTORA, 2018.

Figura 4: Gráfico apontando percentual de Neutralidade maior nos tipos 18 e 21, e menor no tipo 5 e 14 - São Luiz - MA

Nivel de Conforto térmico sob Membrana Tensionada São Luiz - MA (Zona M2)

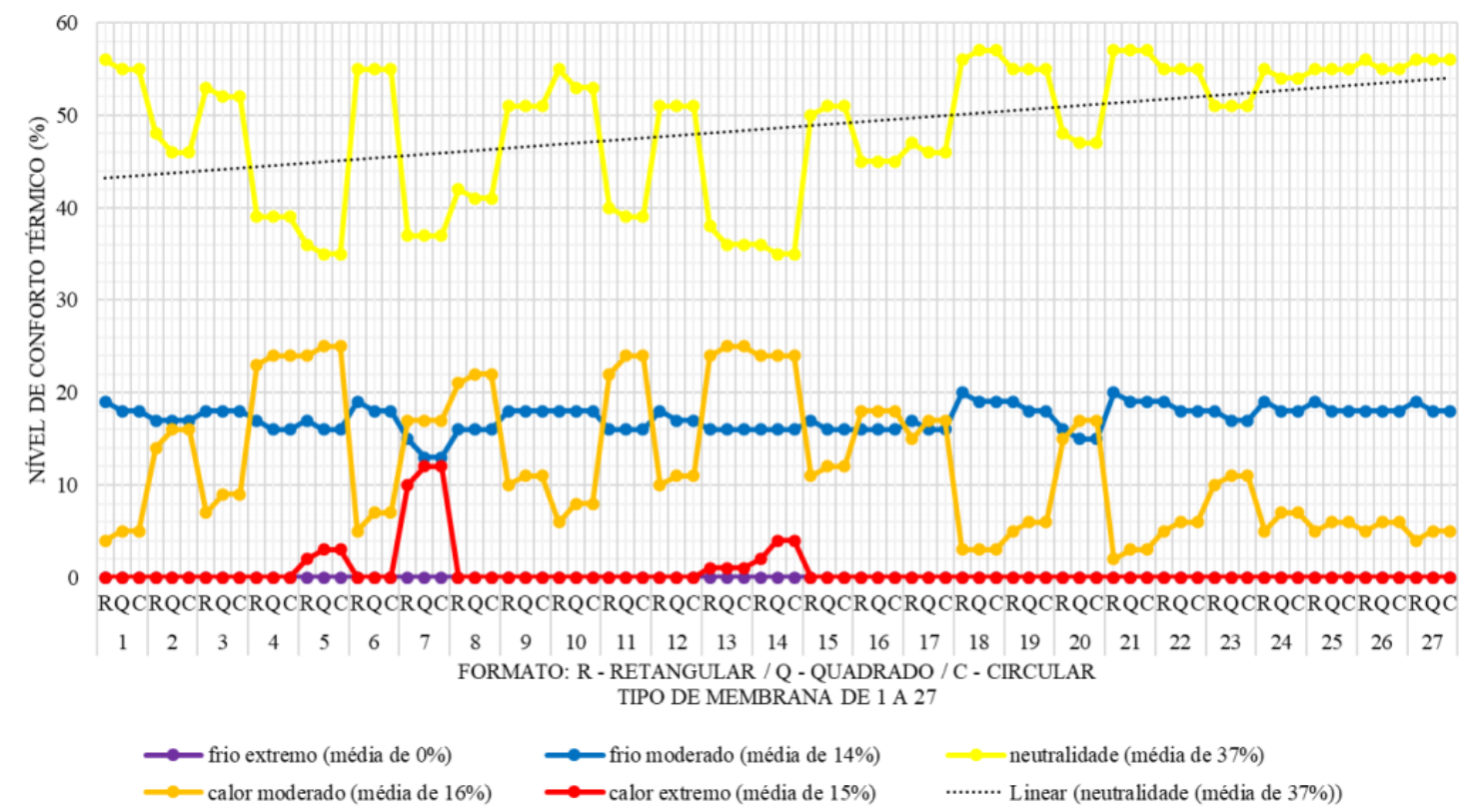

Fonte: AUTORA, 2018. 


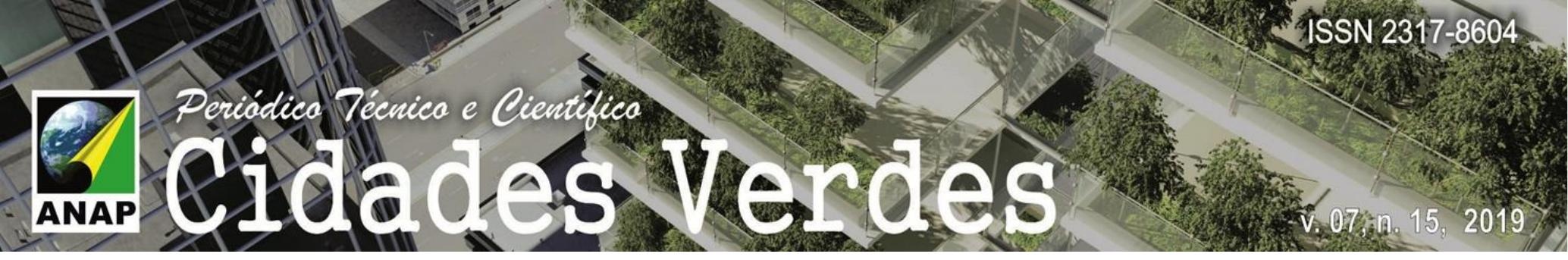

Figura 5: Gráfico apontando percentual de Neutralidade maior nos tipos18 e 21, e menor no tipo 5 - Belém - PA. Nivel de Conforto térmico sob Membrana Tensionada Belém - PA (Zona M3)

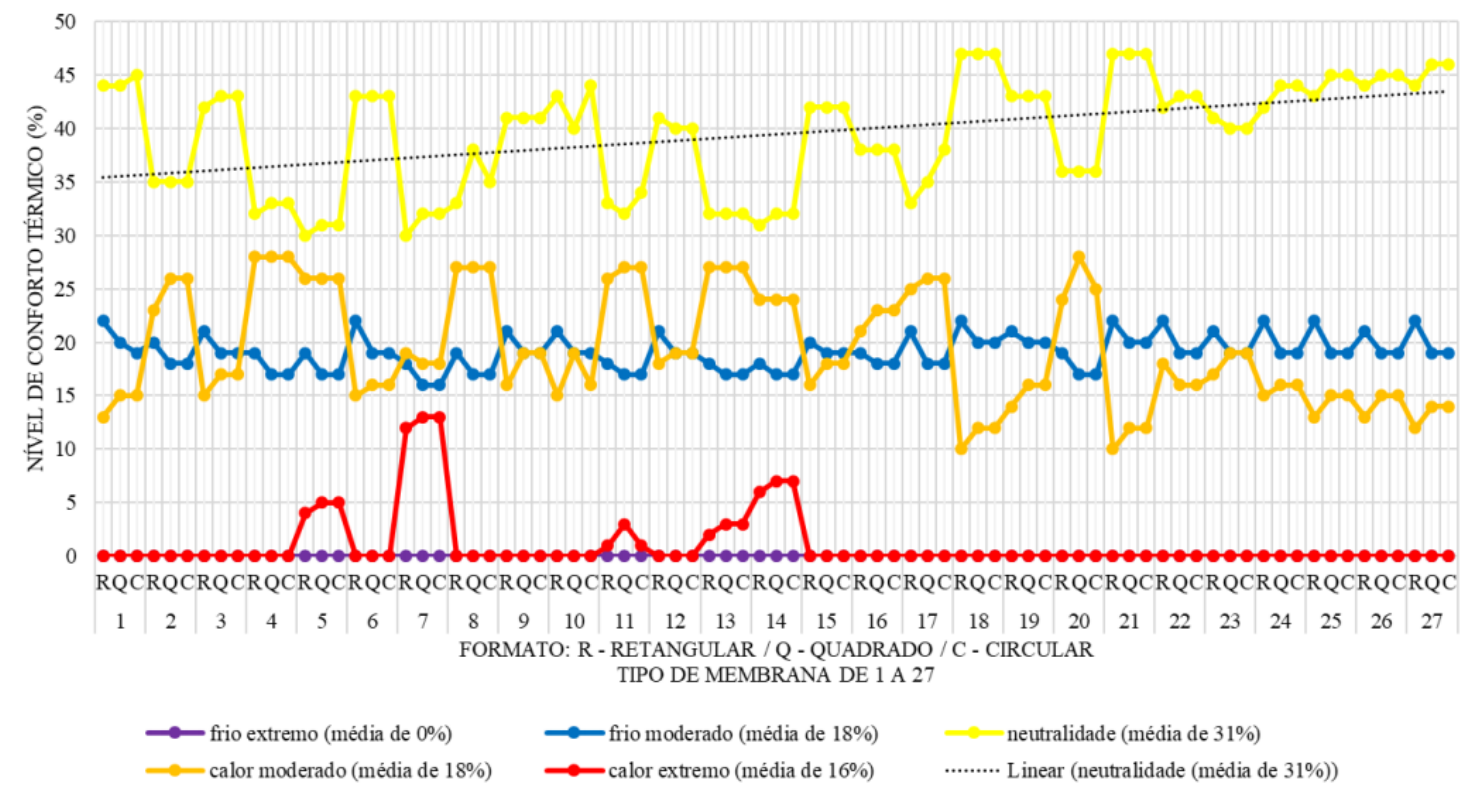

Fonte: AUTORA, 2018.

Figura 6: Gráfico apontando percentual de Neutralidade maior nos tipos18 e 21, e menor no tipo 5 e 14 - Manaus - AM.

Nivel de Conforto térmico sob Membrana Tensionada Manaus - AM (Zona M1)

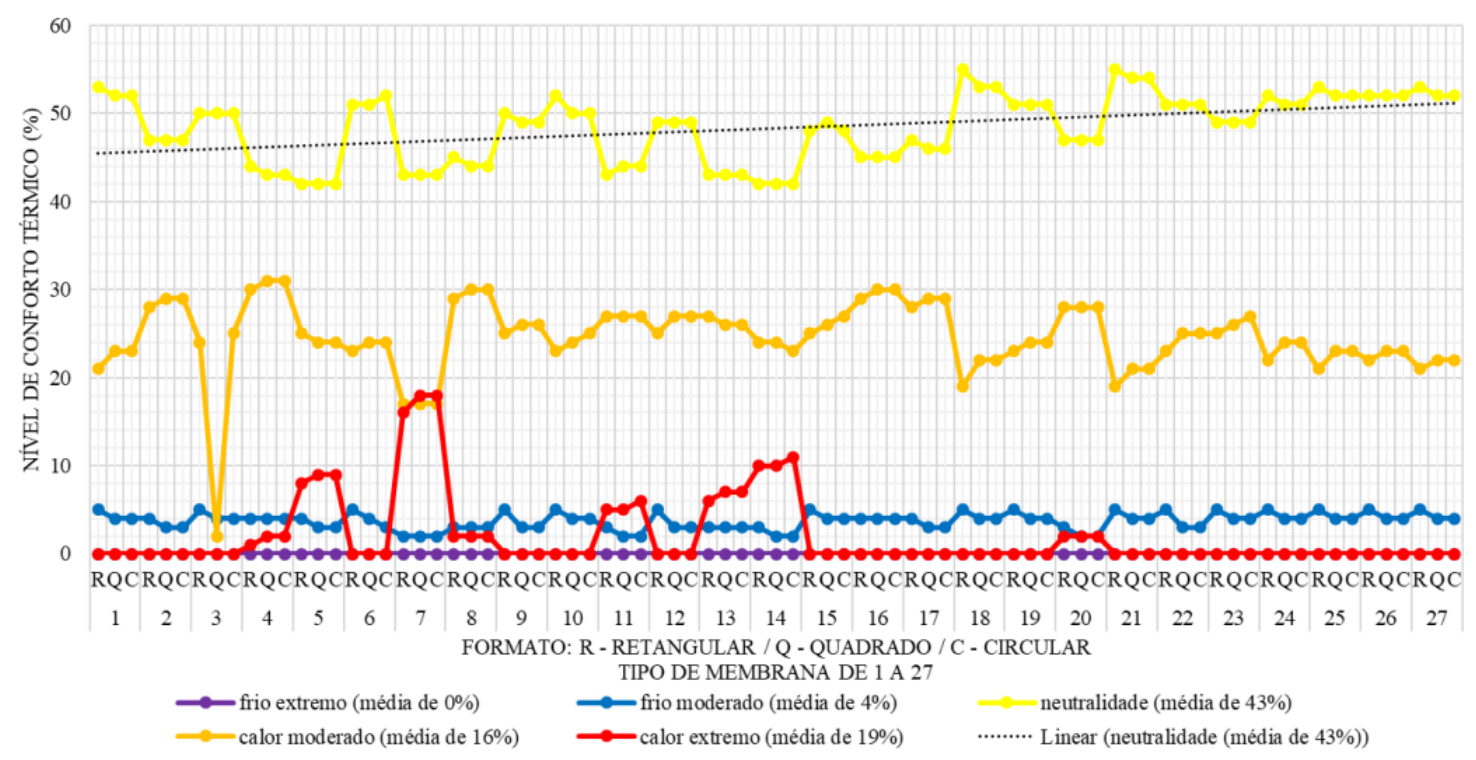

Fonte: AUTORA, 2018. 


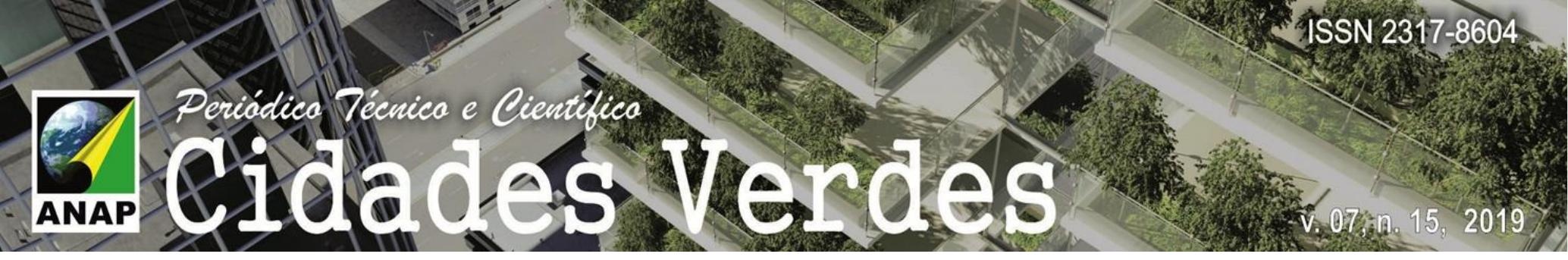

Figura 7: Gráfico apontando percentual de Neutralidade maior nos tipos 18 e 21, e menor no tipo 5 - Marabá PA.

Nivel de Conforto térmico sob Membrana Tensionada Marabá- PA (Zona B1)

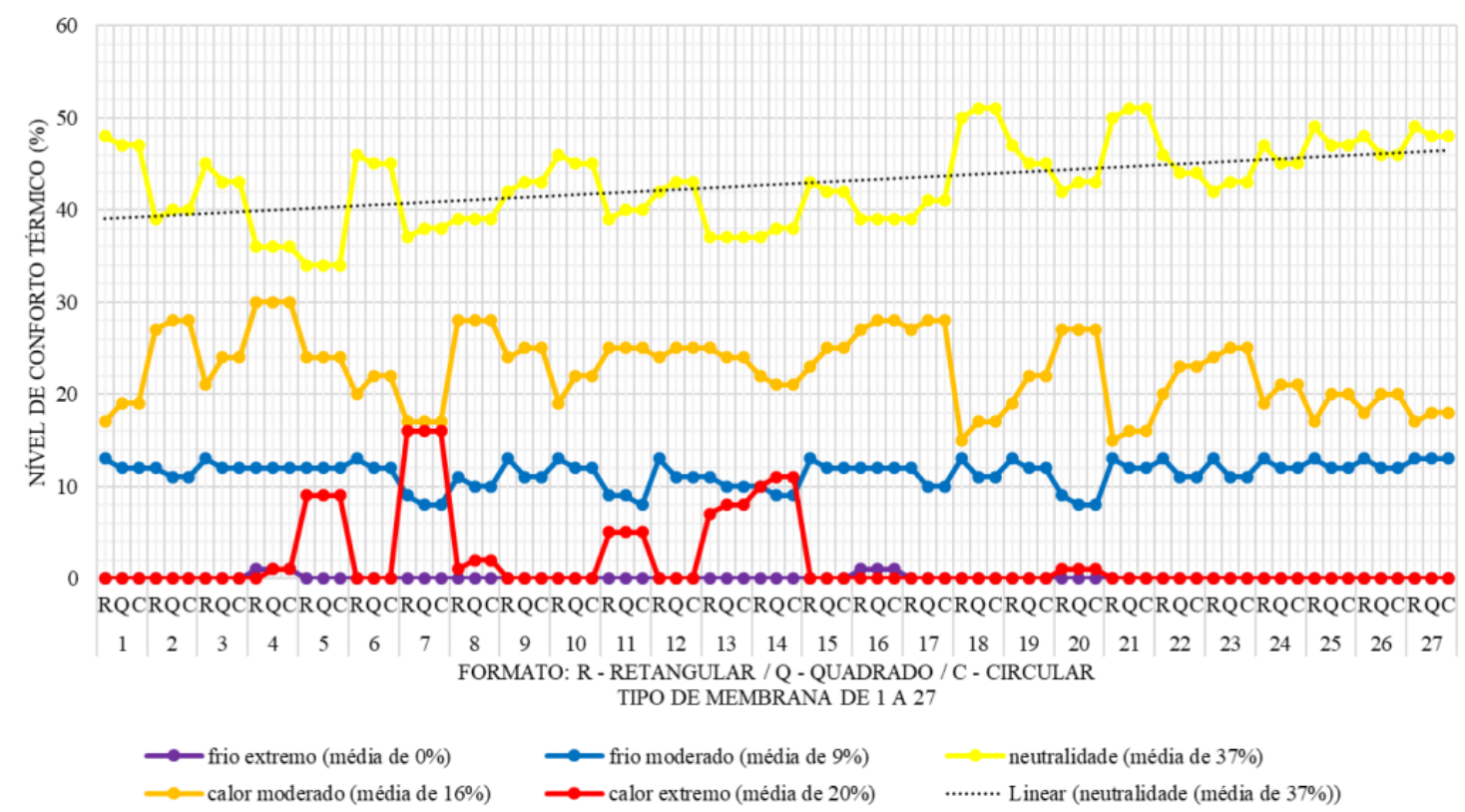

Fonte: AUTORA, 2018

Figura 8: Gráfico apontando percentual de Neutralidade maior nos tipos 18 e 21, e menor no tipo 5 e 14 - Macapá -AP.

Nivel de Conforto térmico sob Membrana Tensionada Macapá- AP (Zona B1)

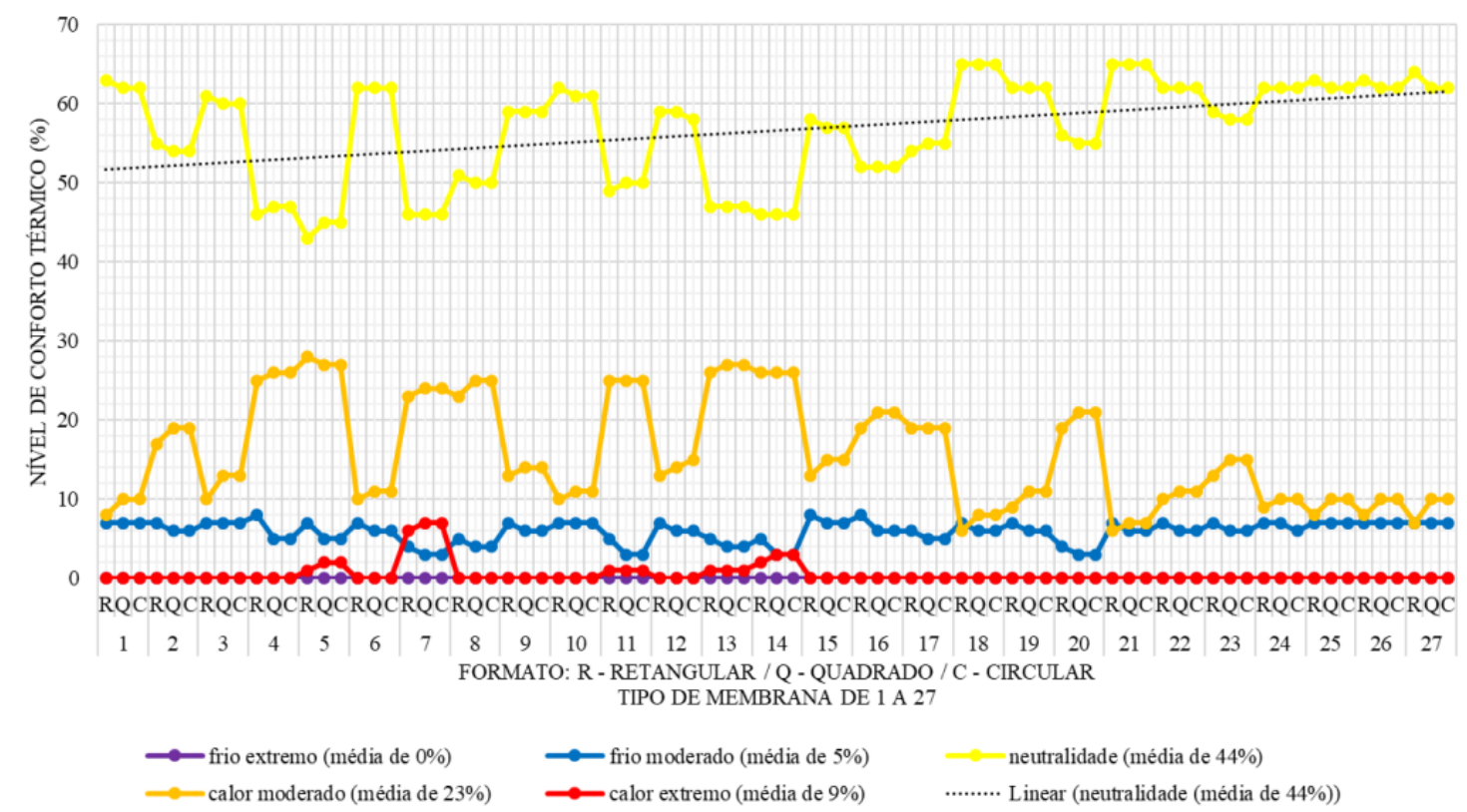

Fonte: AUTORA, 2018. 


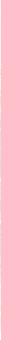

Figura 9: Gráfico apontando percentual de Neutralidade maior nos tipos 18 e 21, e menor no tipo 5 - Porto Velho - RO.

Nivel de Conforto térmico sob Membrana Tensionada Porto Velho - RO (Zona B3)

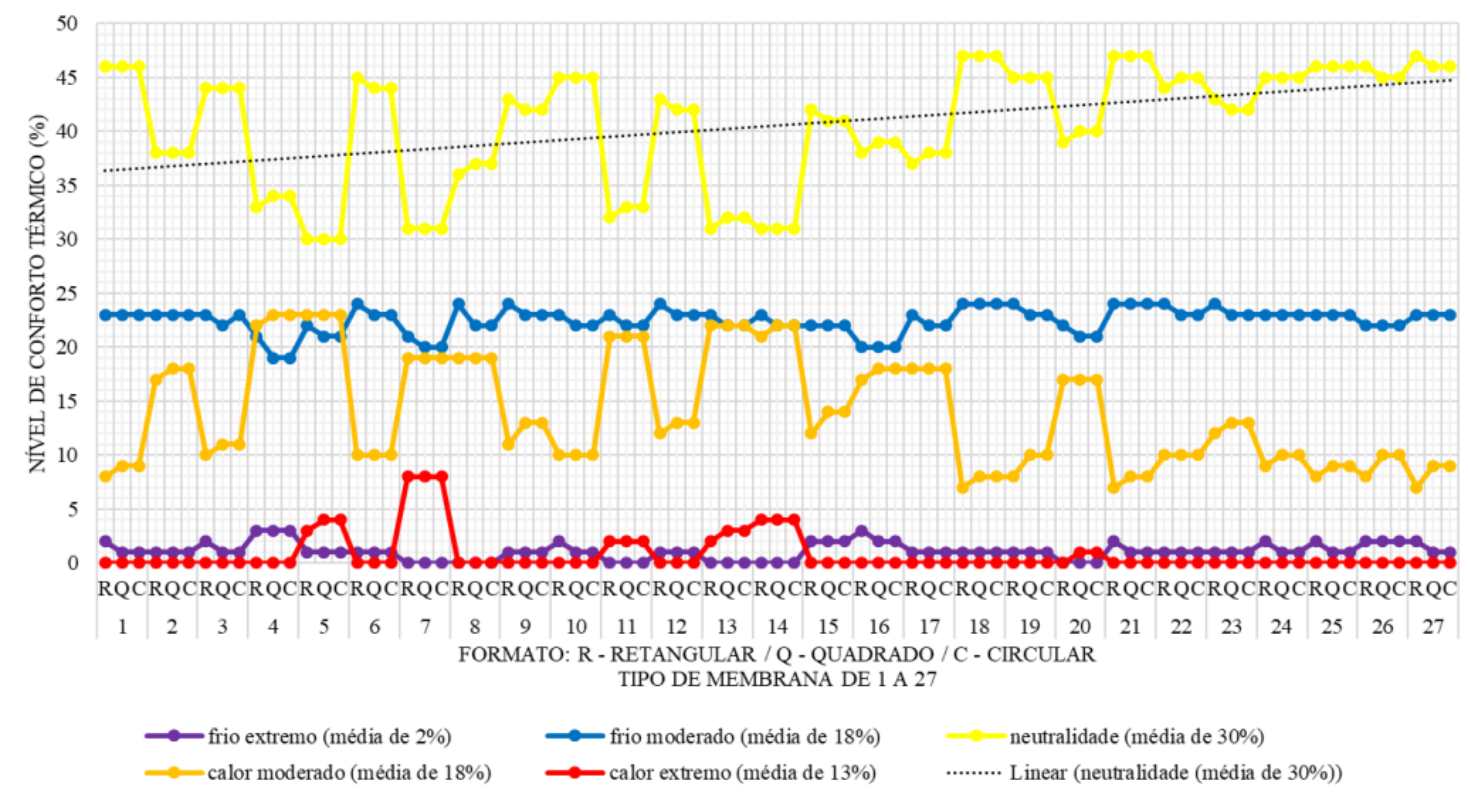

Fonte: AUTORA, 2018.

Nos gráficos também pelas figuras de 3 ao 9 são identificados o tipo 5 e o tipo 14 de membrana têxtil como sendo os menos adequados as serem utilizados na região da Amazônia Legal por obterem os menores índices de Neutralidade. Os dados que substanciam os gráficos podem ser observados na tabela $n^{\circ} 1$. No índice de Neutralidade foi observado que em todos os casos, $o$ percentual foi superior ao apresentado em céu aberto, o que pode ser observado pela legenda, que esclarece qual o índice médio de Neutralidades daquela cidade. 


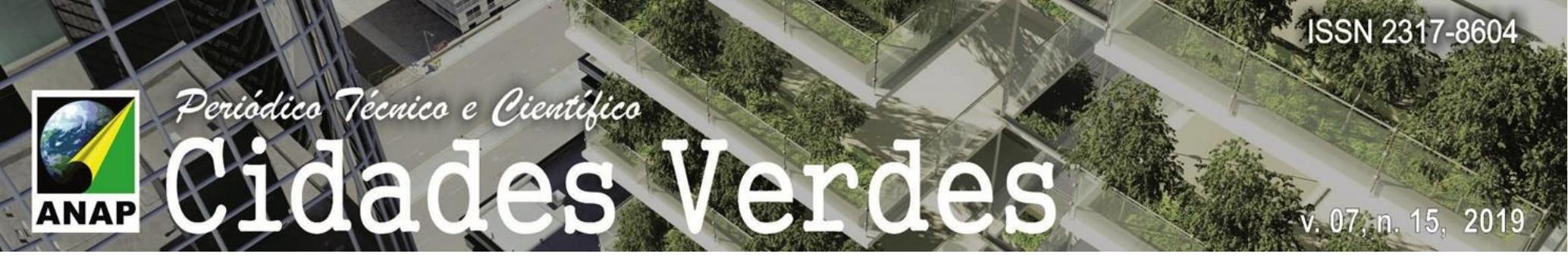

Os índices a serem observados na especificação de membrana têxtil para coberturas tencionadas na Amazônia Legal são Reflexão e Absorção. Quanto maior índice de reflexão melhor o nível de conforto ambiental e quanto maior o índice de absorção menos adequado o nível de conforto ambiental sob estes tipos de instalação. Além de apontar dois tipos de membrana têxtil a serem utilizados em estruturas de cobertura tensionada, descrevendo quais índices de material são mais adequados (absorção, reflexão, transmissão de calor e transmissão de iluminância), na Amazônia Legal também observamos que comparando os índices de material dos tipos 5 e 14 (menos confortáveis) com o 18 e 21 (mais confortáveis) de membranas têxtil, no gráfico da Figura 21, também podemos observar que a escala climática mapeada pelo estudo de Potencial de Agressividade Climática do IBGE (2014) (Anexo A), ilustrado pelas cidades predeterminadas para este estudo, combina com a mesma ordem para classificação dos parâmetros de aceitabilidade da membrana têxtil em relação ao conforto térmico do usuário sob esta tensoestrutura.

Nas Figuras de 12 a 18 dos gráficos, observamos que mesmo alterando o formato da membrana, os índices de sensação térmica permaneciam próximos entre os três formatos (retangular, quadrado e circular). Por isso, podemos afirmar que, o fator determinante para a escolha correta da membrana têxtil a ser utilizada em coberturas tensionadas, está principalmente ligado à sua região climática e suas particularidades de seus dados meteorológicos com o cruzamento de suas características de manufatura entre os 27 tios de membrana têxteis cadastradas no software tensil 1.3. Vale ressaltar que nas cidades de Cuiabá, Belém, Porto Velho e Marabá, somente a membrana têxtil do tipo cinco foi apontada como a menos propensa a oferecer conforto térmico, de acordo com os índices captados no software Tensil 1.3. Como indicado por Fontenele (2006), as características de composição de material da membrana influenciaram de forma especial na sensação de desconforto dos usuários do mercado Ver-o-Peso em Belém - Pa. Então especificar membrana com maior índice de reflexão em comparação a outras opões de mercado seria o ideal para a região da Amazônia Legal. Uma atualização na base de dados do software Tensil 1.3 e a inserção de diferentes condicionantes das edificações de entorno da proposta ou outros parâmetros definidos neste caso poderão destoar dos índices captados neste estudo. E a não utilização deste mesmo software também poderão gerar dados conflitantes. 


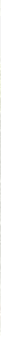

Imagem 1: Gráfico com comparação de índices de material e os tipos mais e menos adequados.

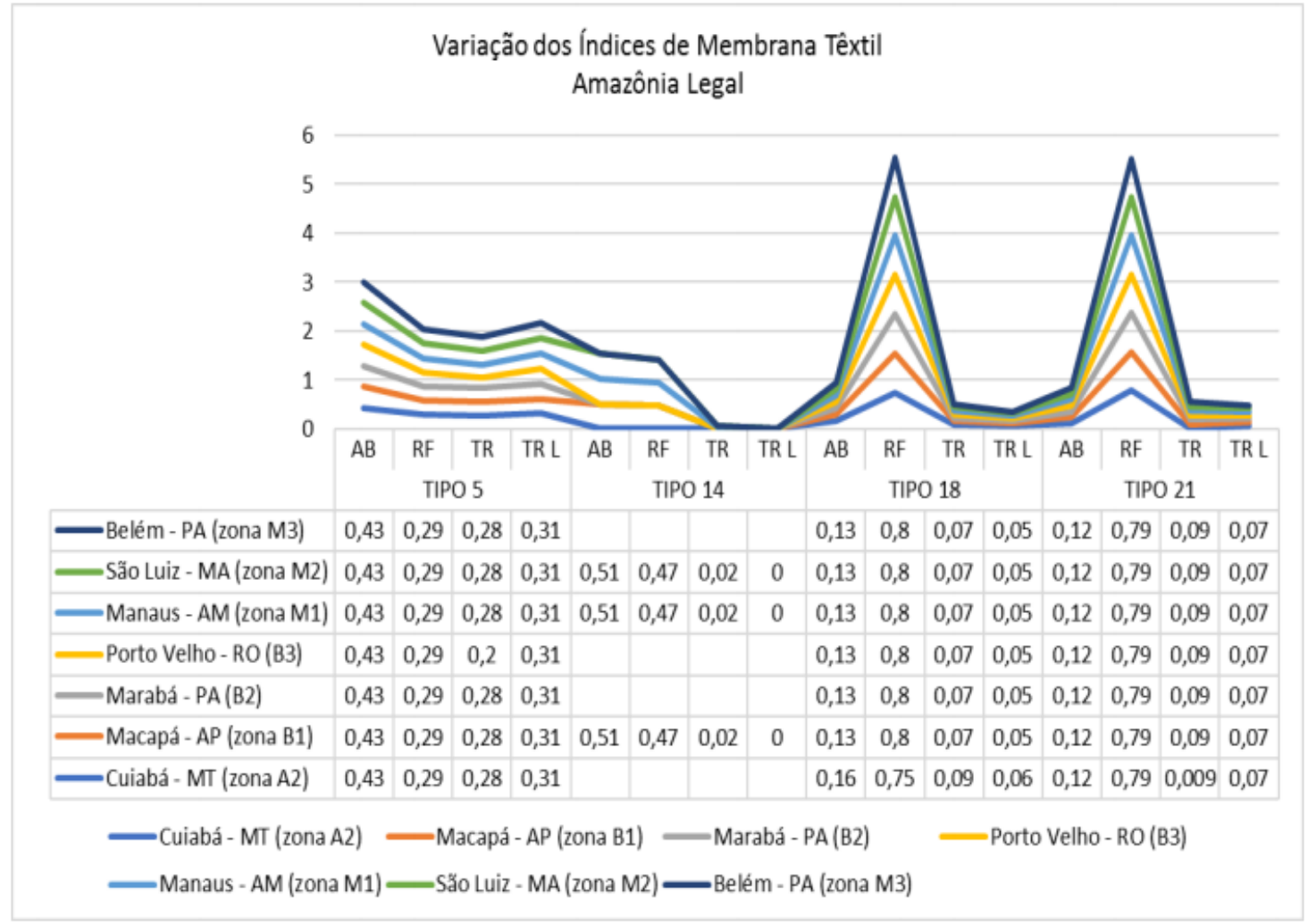

Fonte: AUTORA, 2018

Absorção e Reflexão são os parâmetros a serem observados e comparados entre as opções de membrana têxtil para coberturas tensionadas tendo o índice de Neutralidade como marco para o estudo. Maior índice de reflexão confere melhor conforto ambiental. Maior índice de absorção confere maior desconforto ambiental aos usuários de estruturas de coberturas tensionadas na região da Amazônia Legal. Dentre os 27 tipos de membrana cadastradas no software, os identificados pelos números 18 e 21 são as membranas que melhor se adaptam a oferecer conforto ambiental aos usuários na região da Amazônia Legal. E as identificadas pelos números 5 e 14 são as que menos podem oferecer conforto ambiental na região da Amazônia Legal. Em uma região onde a maior característica climática é o calor, seja durante o dia ou durante a noite, oferecer conforto ambiental é o mínimo que a Arquitetura Sustentável tem a prover. A continuação deste estudo também se torna determinante para que os usuários permaneçam no local com conforto ambiental e é válida por especificar adequadamente o tipo de membrana a ser aplicado nas instalações de cobertura tensionadas com membrana têxtil em todo o mundo, sejam elas instalações fixas, temporárias, de pequeno, médio ou grande porte. Este também pode ser considerado um pedido aos órgãos competentes para o início da adoção de normas para manufatura das membranas têxteis a nível nacional e internacional. 


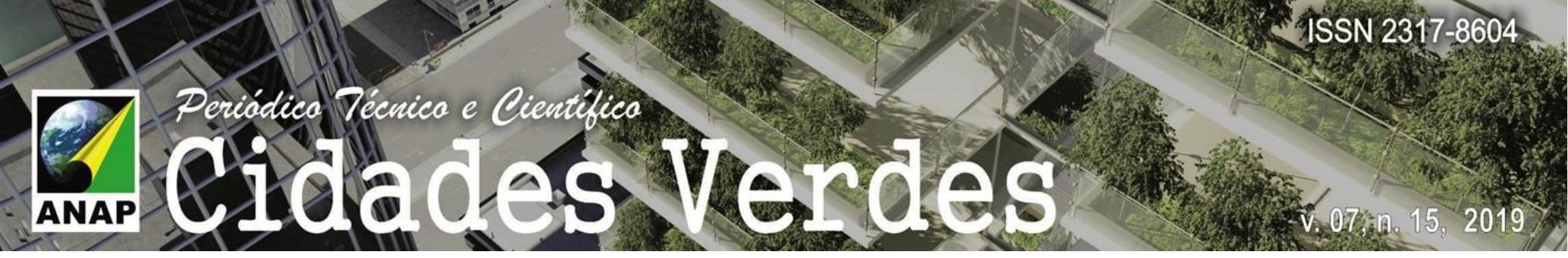

\section{REFERÊNCIAS BIBLIOGRÁFICAS}

ALLUCI, M. P. et al. Uma aplicação computacional para avaliar $\mathbf{o}$ conforto térmico e luminoso sob estruturas de membranas tensionadas. [S.I.: s.n.], [2006].

ABNT - ASSOCIAÇÃO BRASILEIRA DE NORMAS TÉCNICAS. NBR ISO/CIE 8995-1: lluminação de Ambientes de Trabalho - Parte 1 - Interior. Rio de Janeiro, 2013.

BIANCHI, G. M.; TIBIRIÇÁ, A. C. G.; COELHO, L. H. Estruturas de membranas tensionadas. I.: ENCONTRO NACIONAL DE TECNOLOGIA NO AMBIENTE CONSTRUÍDO, 11., 2006, Florianópolis. Anais... Florianópolis: ENTAC, 2016.

ELIAS, B. S. Membranas tensionadas: permanentes ou efêmeras? Revista Assentamentos Humanos, Marília, v. 4, n. 1, p. 59-71, 2002.

FONTENELE, H. B. Uso e adequação de tensoestruturas à região Amazônica - estudo de caso: Feira do Vero-O-Peso em Belém-Pa. 2006. 146 f. Dissertação (Mestrado) - Universidade Federal do Pará, Centro Tecnológico, Programa de Pós-Graduação em Engenharia Civil, Belém, 2006.

FROTA, A. B. Manual de conforto térmico: arquitetura, urbanismo. São Paulo: Studio Nobel, 2001.

IBGE - INSTITUTO BRASILEIRO DE GEOGRAFIA E ESTATísticA. Potencial de Agressividade Climática na Amazônia Legal. Rio de Janeiro, 2014.

Mapa de clima do Brasil. Rio de Janeiro, 2002. Disponível em: <http://geoftp.ibge.gov.br/informacoes_ambientais/climatologia/mapas/brasil/Map_BR_clima_2002.pdf>. Acesso em: 05 de novembro de 2017.

MELO, C. E. L. de; BARBOSA, J. Estudos da modelagem de tensoestruturas: forma arquitetônica e comportamento estrutural. Arquitextos, São Paulo, ano 16, n. 184.03, Vitruvius, set. 2015.

MENDONÇA, Francisco; DANNI-OLIVEIRA, Inês Moresco. Climatologia: noções básicas e climas do Brasil. São Paulo: Oficina de Textos, 2007.

OBATA, S. H.; ALONSO, C. E. Mobilidade das arquiteturas têxteis e tensoestruturas. Exacta, São Paulo, v. 9, n. 1, p. 103-123, 2011.

QUALHARINI, E. L.; ALBUQUERQUE, R. M. de. A tecnologia das tensoestruturas. In.: CONFERÊNCIA LATINOAMERICANA DE CONSTRUÇÃO SUSTENTÁVEL, ENCONTRO NACIONAL DE TECNOLOGIA DO AMBIENTE CONSTRUÍDO, 10., 2004, São Paulo. Anais... São Paulo: ANTAC, 2004.

ROAF, Susan; FUENTES, Manuel; THOMAS, Stephanie. Ecohouse: a casa ambientalmente sustentável. Porto Alegre: Bookman, 2006.

SILVA, C. A. B. e. Modelo computacional para análise da tensoestrutura de cobertura do Centro Comunitário da Universidade de Brasília. 2006. 92 f. Dissertação (Mestrado) - Universidade de Brasília, Faculdade de Tecnologia, Departamento de Engenharia Civil e Ambiental. Brasília, DF, 2006.

VAN LENGEN, Johan. Manual do arquiteto descalço. Porto Alegre: Livraria do Arquiteto, 2014. 